Lastly, a thickened spermatic vein can be divided in mistake for the vas, and when or if orchitis follows, the erring surgeon proclaims the uselessness of duct division as a prophylactic measure!

In those cases where the vas has been divided for the prevention of orchitis, and infection of the seminal vesicles has subsequently occurred, the following signs and symptoms may be observed:

The patient complains of aching in the groin, and has a slight rise of temperature. Palpation of the tissues in the region of the external abdominal ring will reveal a swelling tender on pressure, which may be no larger than a pea or as big as a bantam's egg. The lump is due to the formation of a localized induration of the tissues around the proximal end of the cut vas. So acute was the onset of the symptoms and so sudden the appearance of the swelling at the lower end of the groin in one patient, that the condition was mistaken for a strangulated hernia. These symptoms rarely last longer than a few days unless an abscess forms. When the latter takes place resolution quickly occurs following evacuation of the pus. The transitory constitutional disturbance produced by a small abscess at the point of division of the vas is as nothing compared with pus formation in the testicle. The inflamed vesicle can be felt through the wall of the rectum as a thickened cord projecting upwards and outwards from the upper limit of the prostatic bed. Tenderness is an uncertain sign.

It is clear from the observations which have been made on the mode of spread of infection from the bladder neck and prostatic urethra to the testicle that the effect of division of the vas has determined, once and for all, the channel by means of which bacteria reach the latter. This channel must be either the lumen of the vas or lymphatics within its wall, for the technique of division has consisted solely of breaking the continuity of the duct. Perivasal lymphatics are not.interfered with. Proof of the correctness of this observation lies in the fact that infection from the prostatic urethra, the vesicles, or the prostatic bed, following removal of the gland, terminates at the point of division of the vas deferens.

\section{General Indications}

It is now necessary to consider the indications for this operation as a means of checking the spread of infection to the testicles from the bladder and urethra.

Following removal of the prostate for simple enlargement or any other disease, no technique has yet been devised which prevents some degree of infection in the prostatic bed. So long as this infection exists there is the danger of bacteria spreading from the sump of serum and urine collected in this space, firstly to the seminal vesicles, and thence, via the vas deferens, to the testicle. Thus in all cases of prostatectomy an essential part of the operative technique must be division of the vasa deferentia. The importance to the patient of safeguarding his testicle from infection after he has safely weathered the storm of prostatic disease and the operation of prostatectomy is brought home to the surgeon, who, having failed to divide the vasa, is faced with the problem of treating recurrent attacks of orchitis when he has flattered himself his patient is rid of all his bladder troubles. In urinary tuberculosis when the bladder becomes involved, subsequent complications may be prostatitis, vesiculitis, and urethritis. These organs are affected through the passage of tubercle bacilli in the urine. Once this has occurred there is the further menace of involvement of the external genitalia. It is therefore a wise step, when the prostate and seminal vesicles have been discovered to be tuberculous, to limit the further genital spread of the disease by division of both vasa deferentia. Likewise in genital as opposed to genito-urinary tuberculosis, immediately epididymitis occurs there must be a dissolution of the continuity of the sperm duct to avoid involvement of the accessory sexual organs.

\section{THE ROLE OF MINERALS AND VITAMINS IN GROWTH AND RESISTANCE TO INFECTION * \\ BY}

\author{
ALAN BROWN, M.D., F.R.C.P.(C.) \\ AND
}

FREDERICK F. TISDALL, M.D., F.R.C.P.(C.)

(From the Department of Paediatrics, University of Toronto, and the Hospital for Sick Children)

During recent years more and more attention has been devoted by the medical profession to the role of minerals and vitamins in human nutrition. In the present paper we wish to review some of the work which is being done in this field at the Hospital for Sick Children, Toronto. This work has been undertaken, not with the object of discovering methods for the cure of various disease conditions, but in an attempt to determine the value and importance of these dietary factors for normal development and resistance against disease. There are at least ten inorganic elements which are absolutely essential for life-namely, sodium, potassium, calcium, magnesium, phosphorus, chlorine, sulphur, iodine, iron, and copper. From the standpoint of the practising physician we are fortunate in having to watch the supply of only three of these elements, because any reasonable diet will furnish the other seven elements in adequate amounts. The supply of the three elements calcium, iron, and iodine, however, should not be left to chance.

\section{Essentials in Diet}

Although calcium is the fourth most widely distributed element in the earth's crust, its occurrence in foods is quite limited. Our two chief sources of calcium are milk and leafy vegetables. As regards the child's diet, it may be stated that it is absolutely impossible to furnish an adequate amount of calcium unless liberal amounts of milk are given. This can readily be demonstrated by the following facts. A diet comparable to that found in many uninformed families, composed of rolled oats and breadand-butter for breakfast, beef, potatoes, carrots, cabbage, and rice for dinner, potatoes, bread-and-butter, and honey or jam for supper, with four ounces of fluid milk to go on the rolled oats and rice, supplies only 0.3 gram of calcium. Yet the average 10 -year-old child requires approximately one gram of calcium each day (Rose). The additional 0.7 gram of calcium required can be furnished by one pint of milk per day, or a total milk intake of 24 ounces per day. If all the milk is omitted, the amount of calcium furnished by the remaining portion of the diet is reduced to the absurdly low figure of 0.17 gram. It is thus evident that we depend mostly on milk to supply the large calcium needs of the growing child.

Iron is another mineral element that is not so widely distributed in food that its supply can be left to chance (Sherman). This is particularly true with the small infant, whose diet consists largely of milk and cereal, both of which foods are deficient in iron. Egg yolk, liver, and spinach and other green vegetables are our richest sources of iron in foods. The supply of iodine is probably an easy matter in Great Britain, owing to proximity to the sea. With us, however, in the centre of the North American continent, the iodine content of the water and the food is extremely low. We depend largely on iodized salt to furnish this element.

* Read in the Section of Diseases of Children at the Centenary Meeting of the British Medical Association, London, 1932. 
A lack of vitamin $\mathrm{A}$ in the diet results in a keratinization of the epithelial cells. Our chief supply of vitamin A is butter-fat, egg yolk, carrots, spinach, and cod-liver oil. A lack of vitamin $B_{1}$ results in peripheral neuritis or beri-beri, while a lack of vitamin $B_{2}$ results in pellagra and possibly certain skin diseases. Vitamins $\mathbf{B}_{1}$ and $\mathbf{B}_{2}$ are found largely in yeast, wheat germ, milk, liver, egg yolk, and spinach and other leafy vegetables. Vitamin C, the antiscorbutic vitamin, is found in oranges, lemons, tomatoes, cabbage, and other fruits and vegetables. It is readily destroyed by heat in the presence of oxygen. Vitamin $\mathrm{D}$, the antirachitic vitamin, is not found in ordinary foods, with the exception of small amounts in egg yolk and summer milk. Fish oil, such as cod-liver oil, is our most concentrated natural source. In recent years vitamin $D$ has been produced by the irradiation of ergosterol. Vitamin E, the reproductive vitamin, is found in wheat germ, lettuce, and other leafy foods.

\section{Growth and Resistance in Animals}

In addition to the well-recognized deficiency diseases produced by a lack of vitamins and minerals, we have studied the importance of these food elements on growth and resistance to infection. Each one of these vitamins and minerals is essential for life, so it is only reasonable to expect that if any one of them is omitted from the diet the individual will eventually lose weight and die.

In animal experiments this has been found to be the case. In our rats fed on a normal diet the average gain in weight over a period of six weeks was 100 grams. When calcium was reduced from the optimal figure of 0.612 per cent. to 0.26 per cent. the average gain over the same period was 80 grams. In regard to phosphorus, we found that if this element was reduced from the optimal level of 0.45 per cent. to 0.24 per cent. the animals, instead of making the normal gain of 100 grams in six weeks, gained only 66 grams. With a lack of iron* the rate of gain was reduced 33 per cent. over a period of eleven weeks. Some of the vitamins have been spoken of as the growth-promoting vitamins, but a glance at Fig. 1 shows that a reduction of any one of the vitamins

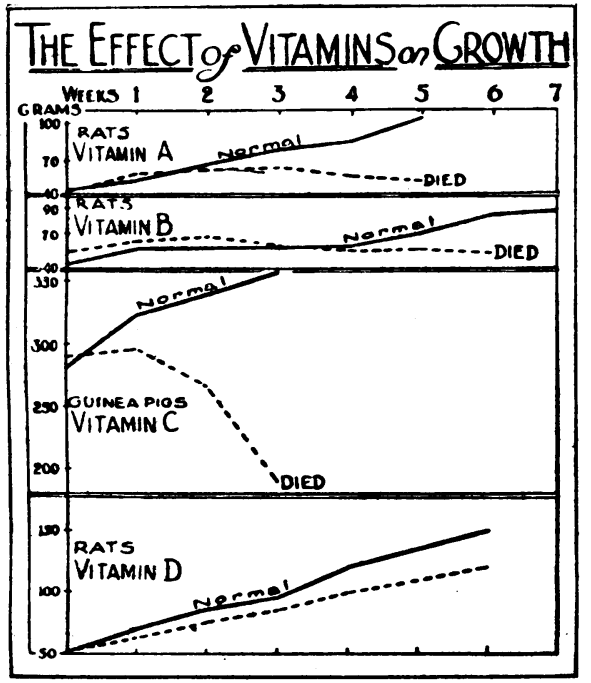

FIG. 1.-The effect of a lack of any one of the vitamins on growth.

(with the exception of $E$ ) results in loss of weight. The influence of vitamin $\mathrm{A}$ in maintaining a normal condition of the epithelial cells of the respiratory tract and normal resistance against infection is so well recognized that this vitamin is frequently called the anti-infective vitamin. By a method devised in our laboratories by Dr. Elizabeth Chant Robertson the effect of a lack of the vitamin B complex and of vitamin $\mathrm{D}$ has been studied. The procedure consisted in

* The effect of an ircn deficiency in lowering resistance against infection in humans has been strikingly demonstrated by Dr. Helen Mackay. feeding the rat the desired deficient diet for a period of two to four weeks, and then giving by mouth a measured amount of an organism pathogenic for the rat, known as Salmonella muriotitis. The animals were then watched for a period of four weeks, and the number of survivors noted. Blood cultures were made from the heart blood of all animals shortly after death, and the very occasional animal which did not show a positive culture was discarded as having died from some other cause. The results given in Tables I and II show

TABLE I.-Effect of the Vitamin B Complex on Resistance to Infection

\begin{tabular}{|c|c|c|c|c|c|}
\hline \multicolumn{3}{|c|}{ Vitamin B Deficient Diet } & \multicolumn{3}{|c|}{$\begin{array}{l}\text { Vitamin B Deficient Diet with } 6 \text { per } \\
\text { cent. Dried Brewers' Yeast Added }\end{array}$} \\
\hline $\begin{array}{c}\text { Total } \\
\text { Number } \\
\text { of Rats }\end{array}$ & $\begin{array}{c}\text { Number } \\
\text { of } \\
\text { Survivors }\end{array}$ & $\begin{array}{c}\text { Percentage } \\
\text { of } \\
\text { Survivors }\end{array}$ & $\begin{array}{c}\text { Total } \\
\text { Number } \\
\text { of Rats }\end{array}$ & $\begin{array}{c}\text { Number } \\
\text { of } \\
\text { Survivors }\end{array}$ & $\begin{array}{c}\text { Percentage } \\
\text { of } \\
\text { Survivors }\end{array}$ \\
\hline 73 & 12 & 16 & 68 & 47 & 69 \\
\hline
\end{tabular}

TABLE II.-Effect of Vitamin D on Resistance to Infection

\begin{tabular}{|c|c|c|c|c|c|}
\hline \multicolumn{3}{|c|}{ Rachitogenic Diet } & \multicolumn{3}{|c|}{$\begin{array}{l}\text { Rachitogenic Diet with Addition } \\
\text { of Vitamin D }\end{array}$} \\
\hline $\begin{array}{c}\text { Total } \\
\text { Number } \\
\text { of Rats }\end{array}$ & $\begin{array}{c}\text { Number } \\
\text { of } \\
\text { Survivors }\end{array}$ & $\begin{array}{c}\text { Percentage } \\
\text { of } \\
\text { Survivors }\end{array}$ & $\begin{array}{c}\text { Total } \\
\text { Number } \\
\text { of Rats }\end{array}$ & $\begin{array}{c}\text { Number } \\
\text { of } \\
\text { Survivors }\end{array}$ & $\begin{array}{c}\text { Percentage } \\
\text { of } \\
\text { Survivors }\end{array}$ \\
\hline 375 & 106 & 28 & 364 & 201 & 55 \\
\hline
\end{tabular}

that a lack of the vitamin $B$ complex and of vitamin D lowers the resistance of rats to infection.

\section{Vitamin D}

As already mentioned, vitamin $\mathrm{D}$ is not present in perceptible amounts in ordinary table foods, with the exception of small and variable amounts in egg yolk and summer milk. Our tests show that eggs procured in the open market in Toronto in the month of March contained as little as two Steenbock vitamin D units per egg yolk. (One drachm of standard cod-liver oil contains 46 Steenbock vitamin $D$ units.) As paediatricians, we see extremely severe rickets in the winter months in infants receiving as much as one quart of milk per day. This makes it plainly evident that the human race does not depend on ordinary foods for its source of vitamin D. As shown in recent years, we depend on the ultra-violet rays of sunshine and skyshine to produce this vitamin in our bodies. We have studied the variations in the antirachitic value of sunshine in Toronto over a period of some years, and found that the antirachitic potency of summer sunshine was approximately eight times as great as winter sunshine. The chief deciding factor in this change in potency is the altitude of the sun above the horizon. It was found that when the sun was below 35 degrees it produced only a slight effect as compared with the effect produced when above 35 degrees. In Toronto, even in the middle of the day, the sun is always below 35 degrees for four months of the year, whereas in the latitude of London this occurs for five months of the year, and in the latitude of Glasgow for six months of the year. This means that in Great Britain the sun has only a slight antirachitic effect for five to six months of the year. This, combined with modern methods of living indoors, and the smoke pall over the large cities, makes it plainly evident that unless some special means are taken the average individual will not receive an amount of vitamin $D$ commensurate with optimal health.

The use of cod-liver oil and other vitamin D products obtained through the drug stores has increased greatly in recent years, with a resultant improvement in the health of the rising generation. We have been accustomed, possibly, to think only of the antirachitic effect 
of vitamin $\mathrm{D}$; the recent work of May Mellanby and others has shown conclusively the value of vitamin D in the prevention of dental caries. It is inconceivable that a vitamin so essential for life in the early years should not be essential throughout childhood and adult life, although in a decreasing amount. Taking all these facts into consideration, we felt that if an additional supply of vitamin $\mathrm{D}$ could be made available to the public, which would be obtained by it at no additional cost, and by no effort on its part, we would be doing something well worth while. Accordingly, we incorporated vitamin $\mathrm{D}$, in the form of irradiated ergosterol dissolved in corn oil, in the shortening used in making bread, so that each 24-ounce loaf contained the vitamin D equivalent of 3 drachms of cod-liver oil. This bread is now being produced in some fifteen cities in Canada and some sixty cities in the United States.

\section{Use of Special Cereal}

It has been stated that cereal grains furnish from 30 to 60 per cent. of the calories of the average diet. Most cereal products as used to-day are highly refined and contain only a small amount of minerals, and are almost devoid of vitamins. This, combined with the rather extensive use of refined sugars, which are quite devoid of both minerals and vitamins, makes it evident that a very severe strain is placed on the remaining portion of the diet to furnish an adequate supply of both vitamins and minerals. In view of these facts, we felt that if an infant or breakfast cereal could be devised which, in addition to supplying calories, would furnish minerals and vitamins in appreciable amounts, it should prove to be a. valuable addition to the average dietary. However, on account of the general preference for refined and finely milled cereals, it was felt that in order to be generally used the cereal should resemble those widely used products in taste, appearance, non-laxative effect, and keeping qualities. Accordingly a cereal has been devised that fulfils these requirements, and has the following composition: wheatmeal (farina), 53 per cent. ; oatmeal, 18 per cent. ; corn meal, 10 per cent. ; wheat germ, 15 per cent. ; bone meal, 2 per cent. ; dried brewers' yeast, 1 per cent. ; alfalfa, 1 per cent.

The wheat germ is used on account of its high protein, mineral, and vitamin content. It contains a moderate amount of vitamin $A$ and is exceptionally rich in vitamins $B_{1}$ and $B_{2}$ and is the most concentrated known source of vitamin $E$. Dried brewers' yeast supplies vitamins $B_{1}$ and $B_{2}$, in addition to the amount already furnished by the wheat germ. Alfalfa is added on account of its high vitamin $\mathrm{A}$ and mineral content. Ve have found that 1 per cent. machine-dried alfalfa furnishes sufficient vitamin A for the cure of xerophthalmia in rats. The iron content of alfalfa is more than $130 \mathrm{mg}$. per hundred grams, which is ten times the amount found in egg yolk, one ot our most concentrated sources of iron in commonly used foods. The bone meal, which is an odourless, tasteless white powder, is used on account of its high calcium and iron content. This cereal mixture has been used exclusively for the past two years in the Hospital for Sick Children, Toronto, and is also extensively used throughout the United States and Canada. In the infant wards, from the standpoint of a laxative, no difference was noted from the results obtained with the refined and finely milled cereals ordinarily used. The palatability of the product was evidenced by its being eaten with the same avidity as the ordinary cereal, not only by the infants, but also by the older children.

A study was made of the rate of growth of children given daily 2 ounces (dry weight) of this cereal mixture in place of ordinary cereals. Some twenty-four children in all were taken, and were divided into two groups, one receiving ordinary cereals in a well-balanced diet, and the other the special cereal mixture in the same well-balanced diet. The children were kept under identical conditions and weighed at weekly intervals over a period of ten weeks. At the end of ten weeks the groups were changed, and the ones on ordinary cereals now received the special cereal mixture and the ones on the special cereal mixture received ordinary cereals. Their weights were observed over an additional ten-week period. The results obtained are shown graphically in Fig. 2. It

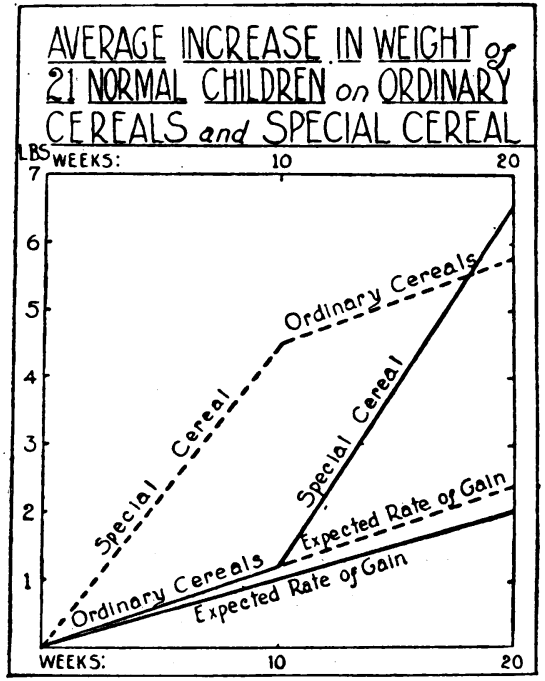

Fig. 2.-Comparison of the increase in weight of children fed on the special cereal and ordinary cereals.

is to be noted that on the special cereal mixture the children gained four to five times their expected rate, in contrast with the average rate of gain obtained while on ordinary cereals.

\section{CONCLUSIONS}

We believe that more care should be taken to ensure an adequate supply of both minerals and vitamins in the diet. The importance of these food essentials in the maintenance of normal growth and resistance against infection is not as widely recognized as it should be. Unfortunately we da not know the exact requirements of these food essentials, nor do we know the exact amounts furnished by many foods. We do know, however, that, owing to the ease with which we can obtain purified carbohydrates, we are apt to suffer from insufficient amounts of minerals and vitamins, and, in occasional cases, of proteins. Nevertheless one can go a long way towards overcoming the deficiencies so frequently encountered in the average diet by building up our meals around five essential articles of food-namely, milk, to supply calcium and protein ; meat, to supply protein ; eggs, to supply protein, vitamins, and iron ; and vegetables and fruit, to supply minerals and vitamins. The remaining calories required can be furnished readily by the refined cereal and sugar products.

After many years of practical experience we are prepared to say that a more widespread observance of these few simple fundamental principles will go a long way towards improving the health of the commlanity, and will materially assist us in reaching that goal which is the keynote of preventive mediciñe-namely, optimal health.

\section{Bibliography}

Mackay, Helen M. M.: Nutritional Anaemia in Infancy, Medical Research Council, Special Report Series, No. 157.

Robertson, Elizabeth Chant, and Ross, John R.: Proc. Soc. Exper. Biol. and Med., 1930, xxvii, 999.

Rose, M. S.: The Foundations of Nutrition, The Macmillan Company, New York, 1929.

Ross, John R., and Robertson, Elizabeth Chant: Amer. Journ. Dis. Child., 1932, xliii, 547.

Sherman, H. C.: Chemistry of Food and Nutrition. Third edition. The Macmillan Company, New York, 1928.

Summerfeldt. Pearl: Amer. Journ. Dis. Child., 1932, xliii, 284.

Tisdall, Frederick F., and Brown, Alan: Journ. Amer. Med. Assoc., 1929 , xcii, 860

Tisdall, Frederick F. Drake, T. G. H., and Brown, Alan: Amer. Journ. Dis. Child., 1930, xl, 791 .

Idem: Canadian Med. Assoc. Journ., 1931, xxiv, 210.

Tisdall, Frederick F., and Brown, Alan: Amer. Journ. Dis. Child., 1927, xxxiv, 721 .

Idem: Ibid., 1928, xxxvi, 734

Idem: Ibid., 1931, xlii, 1144. 